\title{
Cartoons' Effect in Changing Children Mental Response and Behavior
}

\author{
Khaled Habib, Tarek Soliman \\ Jilam Studios PMO, Alexandria, Egypt \\ Email: rdo@Jilam.com
}

Received 4 August 2015; accepted 20 September 2015; published 23 September 2015

Copyright (C) 2015 by authors and Scientific Research Publishing Inc.

This work is licensed under the Creative Commons Attribution International License (CC BY). http://creativecommons.org/licenses/by/4.0/

(c) (i) 0pen Access

\begin{abstract}
Factors that sculpture children's way of thinking are found mostly in the environment where they grow up. These include daily events, memorable experiences and peak feelings. Cartoons are one of the daily habits for our children; studies have proven that an average child with a facility of a TV and a satellite connection at his home watches approximately 18,000 hours of television from kindergarten to high school graduation. How does this experience affect our children minds? Does it have positive or negative effects? What types of contents are delivered to our kids in a cartoonish show? Are all shows trustable, or shall parents pay monitoring attention to the TV shows? How does our children brain absorb and analysis information in the first place? These questions and others will be answered through this survey-experimental research [1] [2].
\end{abstract}

\section{Keywords}

Children, Behaviour, Media, Cartoon, Violence, Sex, Mental, Raising

\section{Introduction}

Cartoons have been a part of cinema history from the time the first motion pictures were made in the late 1800 s. A cartoon is a movie made by using animation instead of live actors, especially a humorous film intended for children (Thompson, 2010). Cartoons can also be described as the making of movies by filming a sequence of slightly varying drawings or models so that they appear to move and change when the sequence is shown. These are the elements that keep viewers, (mostly children) glued to their seats. Cartoons were initially so short because people would be watching these shorts in the movie theatres before their feature film. When cartoonists could put their shows on TV, they began to get longer, creating the half hour block shows that are on Nickelodeon, Cartoon Network, and the Disney Channel today. Also, the cartoons had to become more "family friendly" so that more people would watch their show (Kapelian, 2009). 
Objective: The objective of the paper is to determine the effect of cartoon in changing the mentality \& behaviour of school going children, and the drawbacks in some of the current cartoon TV shows criteria that follow [3].

\section{Cartoon Time in Our Children's Schedule}

In a research performed by the researcher Kayla Bois \& Brad Bushman "Michigan University", they summed up the cartoon content in our Children Schedules as follows:

- 2 - 5 years old children watch cartoon 32 hrs. Weekly.

- 6 - 11 years old children watch cartoon 28 hrs. Weekly.

And they stated that:

- $71 \%$ of 8 - 18 years old has a TV in their rooms.

- $53 \%$ of 7 - 12 years old has no parental monitoring for what being watched on TV.

- $51 \%$ of homes: TV is switched on most of time.

Another research performed by researcher Sharmin "BRAC University", concluded:

- Most parents prefer to leave their children in front of TV in order to finish their Work or to have a rest.

- Putting a child in front of the TV is the best way for a parent to make their child eat their food.

\section{How Does Child's Brain Develop \& Work?}

In a research published on UNICEF's official website, says that there are 3 factors in Child brain development worldwide:

1) There are strong relations between the genes and the brain development; however, the surrounding experience is what sculptures how the brain will function.

2) Thinking and imagination are of the most factors that affect the functionality of the brain till the age of 12 .

3) Early mind setting is the secret, once done, children pattern of future actions could be predicted.

He concluded how human brain "grow" and "work" in early stage as shown in Table 1 below.

It was once believed that the brain's development was pre-determined through genes, and that it growth followed an already determined path > modern research proves that experiences at early ages has an effect on the development of the brain and affects the way which the internal circuits of the brain become connected to each other, which means that a baby's brain is still under development.

Sean Brotherson says: “A child's brain is like a house that has just been built. The walls are up, the doors are hung. Then you go to the store and buy electrical wiring, switches, a fuse box and other electrical supplies, you bring these supplies to the new house and set them on the floor. Will they work? Probably not. You first must string the wiring and hook up all of the connections. This is quite similar to the way our brains are formed.”

The nerve brain cells that an individual is born are as much as 10 times the number of stars in the Milky way Galaxy, or 20 times the number of people on earth, despite that, we will not grow any more than these. But till the day of birth, these cells are still not connected together nor formed a link [1] (Figure 1).

Neurons are the processor of the brain; a neuron is a branched cell body. These branches receive chemical

Table 1. Myths \& facts of human development studies [1].

\begin{tabular}{ll}
\hline Myth & Fact \\
\hline $\begin{array}{l}\text { At birth the brain is fully developed, just like } \\
\text { heart or stomach. }\end{array}$ & $\begin{array}{l}\text { Most of the brain's cells are formed before birth, but most of the connections among } \\
\text { cells are made during infancy and early childhood. }\end{array}$ \\
$\begin{array}{l}\text { The brain's development depends entirely on } \\
\text { the genes with which you are born. }\end{array}$ & $\begin{array}{l}\text { Early experience and interaction with the environment are most critical in a child's } \\
\text { brain development. }\end{array}$ \\
$\begin{array}{l}\text { A toddler's brain is less active than the brain } \\
\text { of a college student. }\end{array}$ & A 3-year-old toddler's brain is twice as active as an adult's brain. \\
$\begin{array}{l}\text { Talking to a baby is not important because he } \\
\text { or she can't understand what you are saying. }\end{array}$ & $\begin{array}{l}\text { Talking to young children establishes foundations for learning language during early } \\
\text { critical periods when learning is easiest for a child. }\end{array}$ \\
$\begin{array}{l}\text { Children need special help and specific } \\
\text { educational toys to develop their brainpower. }\end{array}$ & $\begin{array}{l}\text { What children need most is love, care and new experiences, not special attention or } \\
\text { costly toys. Talking, singing, playing and reading are some of the key activities that } \\
\text { build a child's brain. }\end{array}$ \\
\hline
\end{tabular}




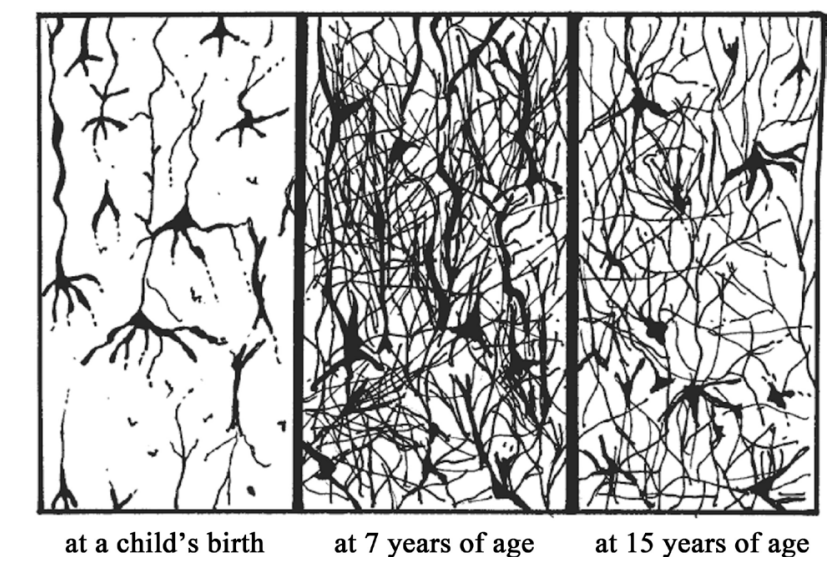

Figure 1. Density of neurons in the human brain at different ages.

signals across the brain, and the impulse travels across the axon. Each Axon has a bag containing neurotransmitters at its end. The electrical impulse releases the neuron transmitter which stimulates nearby branches.

Each cell can connect with about other 15,000 Cells. This network is scientifically named the brain's Circuitry or the brain's wiring. Experience aids in forming the shape of this network a noticeable developing in the synapses occurs during the first year after birth. The brain then develops architecture through the increase of these Synapses Sean Brotherson mentions in his research "For example, if a parent repeatedly calls a child a certain name, then connections will form that allow the child to recognize that name over time as referring to him and he will learn to respond. From birth" [1].

These connections that are formed by the brain create our habits, way of thinking, memories and mind. At the age of 3, a toddlers brain would have created about thousand trillion Synapses, which is nearly double what he would have when he grow to an adult.

The connections that are created in a children's brain are wither strengthen by repeating experience, or are weakened by not being used. Starting at the age of 11, kids start losing the connections that are not used. The ones that are enforced through repeated experiences, does affect the child brain structure and sculpture his way of thinking.

From the above facts we conclude that:

The first experience has its mandatory stamp in the Children's Brain Structure, and consequently the Child's way of thinking and behaviour.

Any experience however less frequent it still has its effect on the brain structure, however repeated actions till the age of 12 are high effective and leave their life time effect.

Experience to the child is what he watches with his eyes, hear with his ears and live through his feelings.

Concluding these above three facts, and the fact that till the age of 12 a child would have watched about 18,000 Hours of Cartoon; this means that the cartoon is one of the main factors that sculpture the human brain, resulting in a predetermined set of way of thinking and behavior.

\section{How Are Children Affected with Cartoons, Why? ... To What Extent?}

Which is better and more relevant that the child would learn from, academic books and teacher, or from a an animated TV Series?

In the research in "Michigan University" performed by Sharmin, she said that children are attracted to the cartoon content much more than the academic traditional ways of learning, due to the well written scenarios, audio \& visual effects and colors. These factors are enough to cause the child to absorb information dozens better than that absorbed from a teacher in a classroom [3].

Child's brain at early ages always seek new experiences, that is why what is delivered in cartoon gets toddlers glued to their chairs while watching Animated Series. A well written scenario, right audio \& Visual effects and a descent looking character, are all the main factors for the child to get stuck for the cartoons hero, and enough for his brain to begin automatically following his path and trying to $\mathrm{b}$ a copycat even for the finest details, including way of speaking, thinking, body language... and even the way of dressing up [4]. 
These are the factors that Traditional schools lack in delivering the academic content, even when a teacher tries to explain a part that children failed to understand, he uses facial expression, acting \& vocal effects for the children to imagine the content. In Animated Series these are the backbones of the show, that is why children chases their best TV series among channels and can sit still for long hours watching TV... easily absorbing the included content [4].

Not even among the child, you can imagine watching a documentary with an academic content on National Geographic Channel, you can easily recall the scenes and the situations that you have watched, much better than a situation that was told with no Visual or Vocal effects.

Consequently, Children who watch educational programming are more likely have higher grades, read more books, place greater value on achievement, and show more creativity than children who watch more violent or purely “entertainment” television (Diehl and Toelle, 2011, p. 3) [5].

So, while children are watching cartoons, there is a form of learning process that is going on. Whatever children learn while watching cartoons, they tend to act out thereby influencing their mode of socializing with other children and with the world in general. Baran and Davis (2009, p. 217).

\section{Experiments Performed to Measure Cartoon Effect on Toddlers Brain}

\subsection{Experiment 1}

\section{Paper Published:}

- Effects of Cartoon Network on the Behaviour of School Going Children (A Case Study of Gujrat City) Conductors.

- Dr. Zahid Yousaf.

- Munham Shehzad.

- Syed Ali Hassan (M. Phil).

\section{Location:}

- India, Gujrat City. Objective:

- Determine the effect of specific cartoon TV shows (Ben Ten \& Doramaan) on the behaviour of school going children.

- Determine the time that children pass watching these TV series.

- Determine the increase in the children's behaviour Aggression after watching these TV series.

\section{Methodology:}

School going Children ranging from the age 7 - 12 were selected from different schools around the city in order to participate in the survey and help in filling a questionnaire.

\section{Sample Size:}

100 Male \& Female School-going Children.

\section{Results:}

Q1. The children were asked about their favorite cartoon TV Show?
A. Ben Ten
B. Doremon
C. Pokemon
D. All of them

Figure 2 shows that nearly $60 \%$ of the children favour Ben ten among the other options.

Q2. What are your daily hourly rate watching cartoons?
A. 1 - 2 hours
B. 2 - 3 hours
C. 3 - 4 hours
D. More than 4 hours

Figure 3 shows that more that $30 \%$ of samples pass more than 4 hours watching TV Series. Though it is considered that cartoon is a favoured way of entertainment for the kids.

Q3. Do you think cartoon characters have psychological effects on children?
A. Yes
B. No
C. Some time

Figure 4 shows that nearly $80 \%$ children have been affected psychologically after watching cartoons.

Q4. Do Children behave differently after watching cartoons?
A. Yes
B. No
C. Some time

Figure 5 shows that $60 \%$ children behave differently after watching cartoons, as much as children give attention to the cartoon and the characters, their behaviour vary.

Q5. Do children change their spoken language or accent after watching the cartoon?
A. Yes
B. No
C. Some time 
Figure 6 shows that more than $60 \%$ of the children are changed their language and accent after watching cartoons. That is because children get affected with the cartoon character and start copycatting them in every possible way including the way of speaking.

Q6. Have you noticed increase in fighting between children after they watched the cartoons?

\section{A. Yes $\quad$ B. No C. Some time}

Figure 7 shows that more than $60 \%$ of the children behaviour changed after watching cartoons, as they start fighting with each other using the same skills and techniques applied by the cartoon characters.

Q7. Do children prefer watching cartoons to outdoor games?
A. Yes
B. No
C. Sometimes

Figure 8 shows that nearly $60 \%$ of the children prefer watching cartoons to outdoor games this means that the entertainment gained by the cartoon is much higher than the physical entertainment the children enjoy from outdoor playing or going to a picnic.

Conclusion:

The conductors of the experiment concluded that Cartoon TV Series has great Influence over the children. A cartoon has the major portion of the children attention and time more than any activity the child performs. In modern life, where the parents are busy with their work, much less time portion of their time is given to their

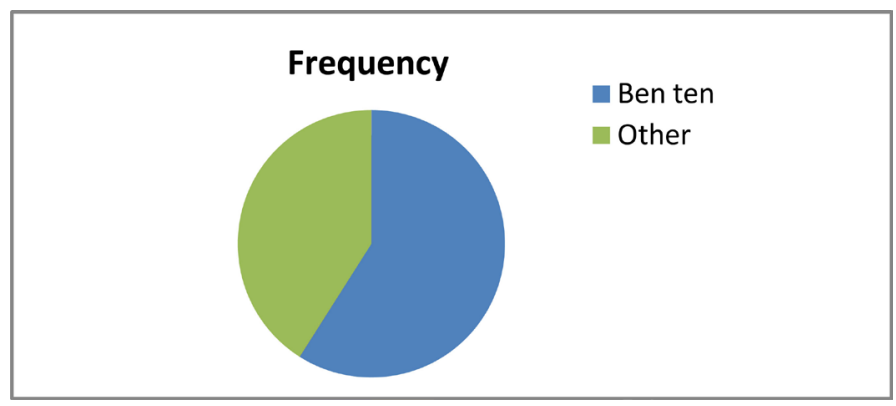

Figure 2. Children favoured TV series.

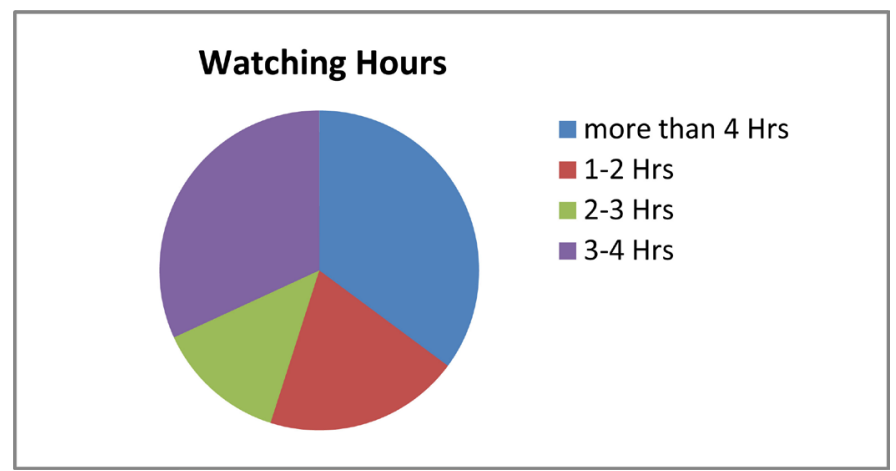

Figure 3. Children daily watching hours for cartoon series.

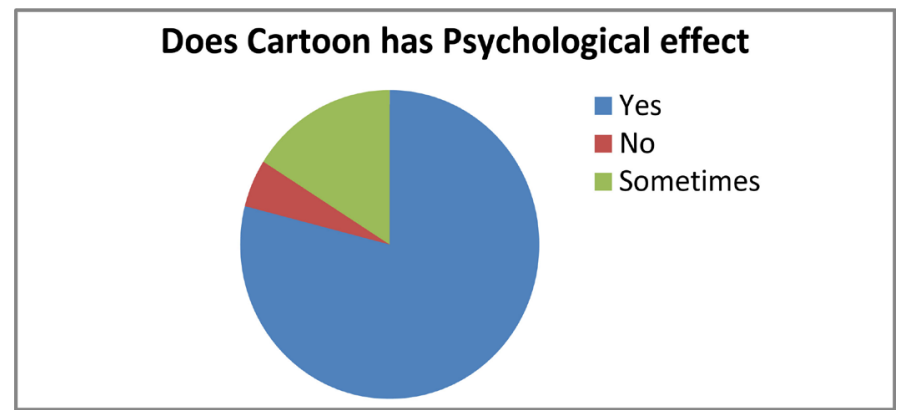

Figure 4. Psychological effect of cartoon on children. 


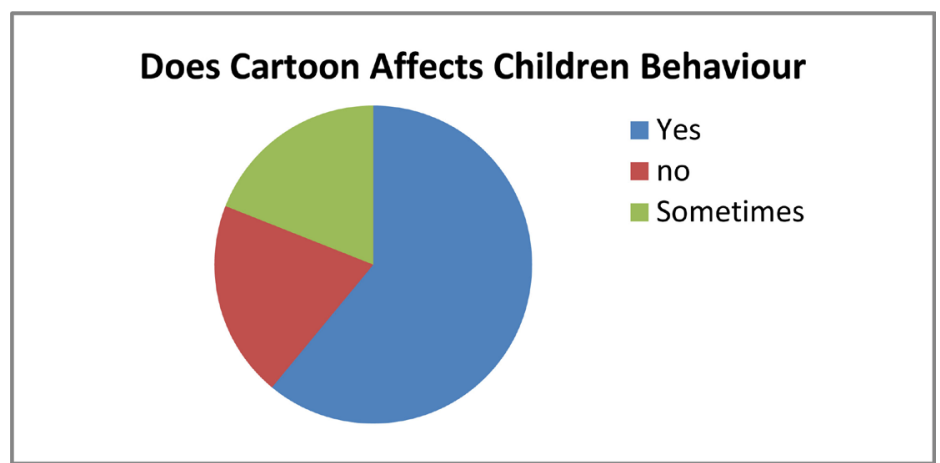

Figure 5. Effect of cartoon on children behaviour.

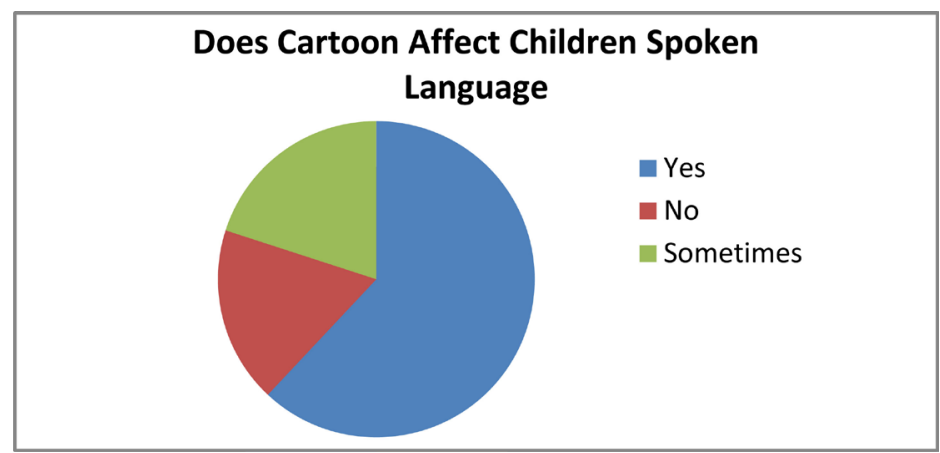

Figure 6. Effect of cartoon on children spoken language.

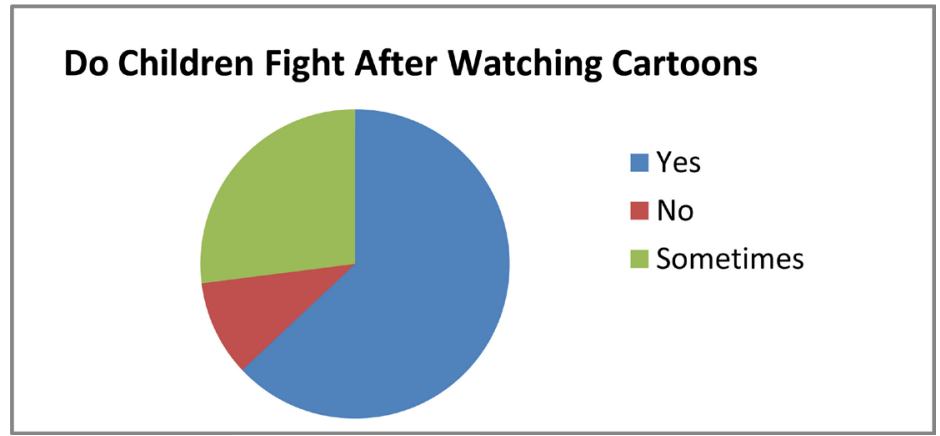

Figure 7. Children aggressive behaviour after watching cartoons.

\section{Children prefer cartoons to outdoor games}

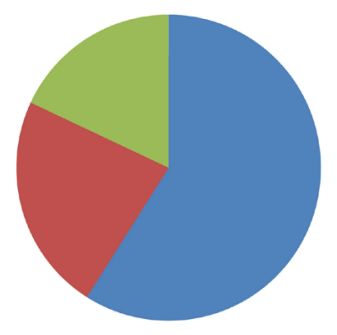

yes

No

Sometimes

Figure 8. Children preference between cartoons and outdoor games. 
children, so mostly this time is passed in front of a cartoon TV series. The survey also proves the great effect of cartoon on children behavior. As well as cartoons do change the children behavior, it also changes their spoken language, as they intend to intimate the cartoons character.

\subsection{Experiment 2}

\section{Conductors:}

- Hassan \& Danial.

Location:

- Pakistan.

Sample:

- 300 Child (6 - 13 years old).

\section{Methodology:}

The children were given questionnaire based on Clara and Marian (1980).

Work and researcher also explained all the questions asked in the questionnaire. The data were analyzed by using non-parametric test in Statistical Package for Social Sciences (SPSS) software version 15.

Hypothesis:

- H1: Behaviour of school going kids in class is influenced by the frequency they watch cartoons.

- H2: Violence presented in the cartoons influence the behaviour of the children.

Result:

1) For testing the first hypothesis, we used the chi-square test of association to measure the strength of relationship between the behaviour of the children in class and the frequency they watch the cartoons. The study showed that the result is significant at $5 \%$ confidence level because $\mathrm{p}<0.05$ (Table 2).

2) For testing the second hypothesis, that the behaviour of children is influenced by the violence presented in the cartoons, the chi-square test of association was used. The study gave the significant result at $p<0.05$, so we can come to the conclusion that the violence present in the cartoons has strong association with the behaviour of the children (Table 3).

\section{Conclusion:}

The conclusion of the experiment as mentioned by the conductors, is that In the current era of powerful media, the children also affected by their most favourite program on television i.e. cartoons. To conclude the recent study, we can say that there is a strong impact of Cartoon Network on school going kids which can be seen on their life style, dressing, aggressive and violent behaviour and their language. We found from our study that most of the kids i.e. 80 percent often spend their time in watching cartoons and more over Cartoon Network is the most favourite cartoon channel of 84 percents children. Most of the students i.e. 65.2 percent spend daily 1 to 3 hours in watching cartoons on television in their leisure time. So it can be said in view of above mentioned facts that cartoon watching is the most favourite hobby of the children. It is also revealed from the study that Tom and Jerry and Loony Tunes are ranked by the kids 1st and 2nd with the average of 35.8 percent and 23

Table 2. Chi-square result of the study.

\begin{tabular}{cccc}
\hline & Value & Degree of freedom & p-value \\
\hline Pearson chi-square & 6.75 & 2 & 0.03 \\
Likelihood ratio & 6.93 & 2 & 0.03 \\
Linear-by-linear association & 6.22 & 1 & 0.01 \\
N of valid cases & 300 & & \\
\hline
\end{tabular}

Table 3. Chi-square result of the study.

\begin{tabular}{cccc}
\hline & Value & Degree of freedom & 4 \\
Pearson chi-square & 32.00 & 4 & 4.00 \\
Likelihood ratio & 27.19 & 23.79 & 1 \\
Linear-by-linear association & 300 & 0.00 \\
N of valid cases & & \\
\hline
\end{tabular}


percent respectively. The most favourite cartoon character of the school going kids is Jerry with 41.2 percent.

\subsection{Experiment 3}

Conductor:

- Siripen Iamurai-King Mongkut's University of Technology Thonburi, Bangkok, Thailand.

Location:

- Thailand.

Sample:

- 200 Primary School going kids.

\section{Objective:}

- To test the effect of positive cartoon content on the children and their behaviour in manner and academically in school.

\section{Methodology:}

Pretest of the samples, then treatment using a positive carton content is applied which encourage the children to act in a behaved manner and to be ready to learn from their teachers in school, than a Post test is done for the samples after the treatment... then finally an interview is performed.

\section{Research Design:}

Type of research is experiment and survey.

\section{Identification Variable:}

There are two type variable in this research:

Independent variable: Sample of The Positive Cartoon Animation.

Dependent variable: Children behavioural Change.

Results (Table 4):

- Younger group (Grade 1-2) can be changed behaviour the most than other groups.

- Middle group (Grade 3-4) can be changed the least.

- The children who like the treatment have the potential to change behaviour more than.

- Children who dislike.

- Mostly of sampling like the treatment (Sample Cartoon Animation).

\section{Conclusion:}

As being mentioned by the experiment conductors Media—specially cartoon—has its strong effect on the children which can be positive, if the correct cartoon content is used.

\section{What Are the Pros \& Cons (Sex \& Violence) of Cartoons Content}

Regarding the above facts, Cartoons proves to be having a huge space concerning our Children Daily Schedule and weights a lot in the first experiences that sculpture the children brain.

\section{Table 4. Cross tabulation of grade*behaviour change.}

\begin{tabular}{|c|c|c|c|c|c|}
\hline \multicolumn{6}{|c|}{ Grade*behavior change crosstabulation } \\
\hline & & & \multicolumn{2}{|c|}{ Behavior change } & \multirow{2}{*}{ Total } \\
\hline & & & Change & Not change & \\
\hline \multirow{6}{*}{ Grade } & \multirow{2}{*}{ Younger } & Count & 54 & 4 & 58 \\
\hline & & \% within grade & $93.1 \%$ & $6.9 \%$ & $100.0 \%$ \\
\hline & \multirow{2}{*}{ Middle } & Count & 47 & 13 & 60 \\
\hline & & $\%$ within grade & $78.3 \%$ & $21.7 \%$ & $100.0 \%$ \\
\hline & \multirow{2}{*}{ Higher } & Count & 72 & 10 & 82 \\
\hline & & \% within grade & $87.8 \%$ & $12.2 \%$ & $100.0 \%$ \\
\hline \multirow{2}{*}{ Total } & & Count & 173 & 27 & 200 \\
\hline & & $\%$ within grade & $86.5 \%$ & $13.5 \%$ & $100.0 \%$ \\
\hline
\end{tabular}


Now comes the question, does this content have a Positive or negative effects on the children brain?

A strong tool like cartoon, could be a double edged weapon, it could be positively used to create a character with good deeds to lead the kid mind to think positively of the society and his surroundings, and to take the right recreations even to worst Actions [6] [7].

\subsection{Positive Effect}

Positive effects of cartons on a child could be analyzed in long articles, here under by just a few key points to be mentioned.

Socially, a positive cartoon could be used to tech a child how to control his temper, obey his parents, speak in a polite way, help the poor, aid the old, lend hand to the young and to work in a group without feeling hatred or jealous from his colleagues.

Speaking about the skills, a positive cartoon content could teach a toddle how to be a leader, how to analyze problems in a scientific manner, how to manage a risk, think about acting and eve to cause a kid to love a sport.

Concerning life experience, a well built cartoonish scenario could teach a child about dangers of the surrounding environment like the heights, fire of the oven, danger of electricity, crossing the streets also could teach him Scouts skills, like how to act in the wild, heal a wound, deal with a broken arm, know the way of the wind, make a compass, build a small boat, set a tent and correctly tangle a rope.

All these and much more are skills that could be filled in a cartoon and absorbed by the child brain if it is delivered in a correct attractive way. A Cartoon hero could be the child's model for years.

A cartoon hero is built by an illustrator as well as the scenario, so all negative side effects that could occur in a real life- that could be presented in a character or in a situation—could be evaded, causing the child to receive a pure content of good deeds and messages to correctly sculpture his brain [3] [4].

\subsection{Negative Effect}

On the other hand, a cartoon could be much more dangerous than any other experience a child could witness before the age of twelve. It could contain content that would confuse the child with what he experiences in real life, it could contain directions that contradicts with the parents orders. A flawed cartoon could lead a child to have a different undesirable point of view of his parents, his friends, teacher and even his lord [8].

Negative content—on purpose or mismanaged—could lead a child to doubt his raising, his skills, way of thinking, life style that he grown up according to or his religion. A character with negative attitude and manners that appears on the screen as a hero, could illustrate the child to vice versa his understandings of his life and surroundings and sculpture his acts in an aggressive or over acting manner to situations he formerly acted positively due to his correct understanding then [8] [9].

In this research we will focus on the two most dangerous factors that could be included in a cartoon to be delivered to the child, in which researches has proven their dangerous direct effect on a child... they are Sexuality \& Violence.

\subsubsection{Sexual Content}

One of the most undesired factors that could be present in a cartoon show is the presence of sexual content. How this could be present in an animated series? And what are its side effects?

Let's have a quick review on the human brain, the human brain is divided into two main parts one is the conscious mind simply called the "Human brain", this is the part of brain which you are currently using to read this sentence. This part is responsible for analyzing, calculating \& logical thinking, and this part is specialized for human rather than any other living organism. The other part is the unconscious called the "Animal Brain", it is named so because it is a common brain part between human and animals, this part is responsible for a number of purposes, two of these purposes are, first is the memory, and the second purpose is maintaining the actions and habits that guarantees the continuity of the species without being exposed to extinction, these actions are mainly "Sex \& Food".

That is why these two actions "sex \& food" provides a human body with top joy. This joy is felt through the production of special chemicals. This occurs due to chemical process that takes place inside the brain, one of these hormones is called Dopamine, which is well known among scientists as "The Molecule of Addiction". 
So what are entries methods to the brain? Human brain would analysis incoming data from all senses of the human body, this includes visuals seen by the eye, and audio heard by the ears. This data is transferred through cannels from the eye \& the ear to the human brain through electric pulses passing among the neurons, once this data contains Sexual content, the animal brain would be triggered causing that special chemical process would take place and the Hormones that cause Joy to human body are produced.

This pokes another question, what are the sexual content that if witnessed by the human eye would trigger those chemical reactions? By Nature, the Animal brain of each Human gender is attracted to the anatomy and organs of the other gender. So in case of a male human, he is attracted to body features that is present in a female human body including non-flattened chest, curved thighs, buttock \& the reproductive organ. While in case of a Female human, the animal brain is naturally attracted to body \& Facial hair, stretched muscles \& the reproductive organ. In case these parts are witnessed by the eye in a seductive way, this would trigger chemical reactions to take place.

Another fact about the human brain is that it does not differentiate between what is virtual and what is real. In other words, if a scene is witnessed on TV the human brain will react to it as if it was for real. This explains why we feel hungry when we see a sandwich Ads on TV, why we feel afraid while watching a frightening scene, and why we Human males are poked when a man see a beautiful seductive girl on the screen. Although our conscious mind "Human Brain" does realize that this is just a picture and what he sees is just electronic display, our "unconscious mind" does not analyze this signal this way, instead it begins to react to what it has just witnessed as if it has seen a real girl.

Adding these two pieces of information together, when a male human eye witnesses a Girl on TV in an attractive position, the human brain will begin to react to the incoming information, it begins to give order to the rest of the body organs to be prepared for fertilization and be ready for having babies, and vice versa occurs with the female human. This is exactly how the human brain works in witnessing the other gender.

How is this piece of information involved in the cartoon show? Cartoon content recently had the characteristic of including attractive sexual content under the name of comedy and action. This entry has its side effects on the child's brain much more than the benefit of drawing smile on their faces. Part of modern cartoon comedy is the sexual comedy present in Seduction \& Harassment, directors' Focus on the human anatomy in order to unique his product or to improve level of Comedy or Action present in the show.

This sexual content triggers early toddlers mind to be attracted to the opposite gender anatomy. Several sexual content in the cartoon causes a psychological case called Novelty, in which Dopamine "Molecule of Addiction" is triggered and produced continuously without limitations this leads to brain dysfunction as the fertilization process is always on alert and triggered several times in a short interval o time and from different entries.

Here we do attach some of the examples of included sexual content present in well known shows and that are aired in popular TV Cartoon Channels.

\subsubsection{Examples of Sexual Seductive Content in Modern Cartoons}

\section{Example 1}

Show: Symbiotic Titans.

Channel: Cartoon Network.

In that scene the girl dances in an attractive way to convince the man to make the Homework instead of her, she turns on a DVD and starts dancing for about a minute, focusing on her lower body (Figure 9).

\section{Example 2}

Show: Hercules.

Channel: Nickelodeon.

In this scene the Girls of that concept are known for their dynamic waist-accompanied by a very thin body - which nearly move with every emotion and camera capture, this mobilization is what catches the eye due lack of rest of body organs motion with this type of rigging (Figure 10).

\section{Example 3}

Show: Digimon.

Channel: TV Kids \& others.

These are several female characters from different Digimon seasons; feminine organs are explicit on most episodes (Figure 11). 

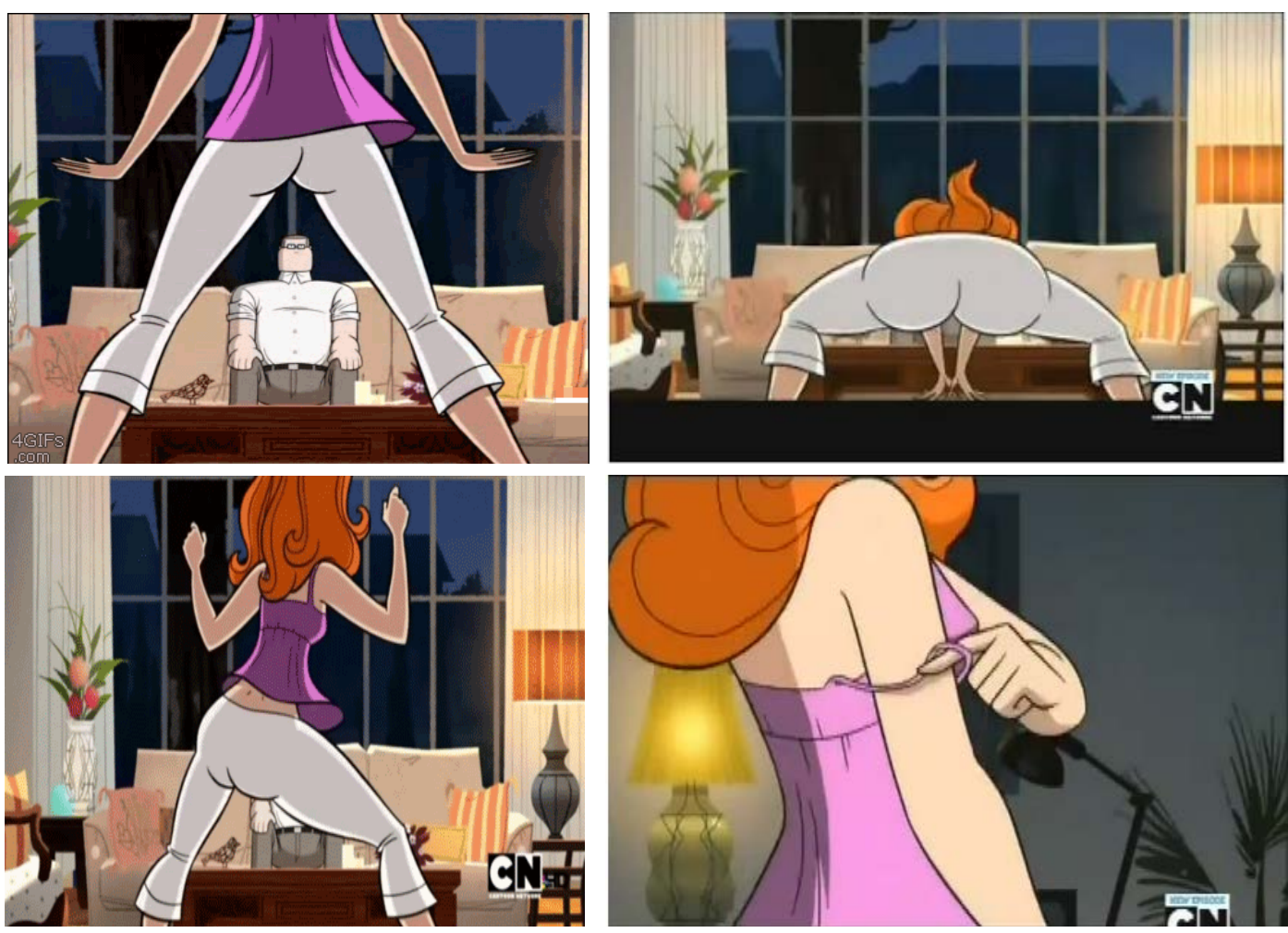

Figure 9. Shots from Symbiotic Titans TV show.

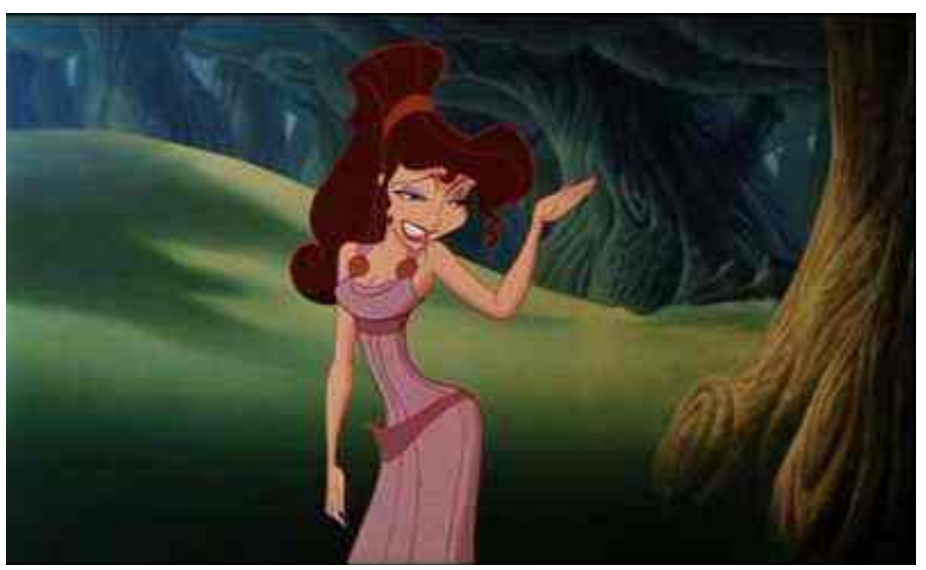

Figure 10. Shot from Hercules movie.
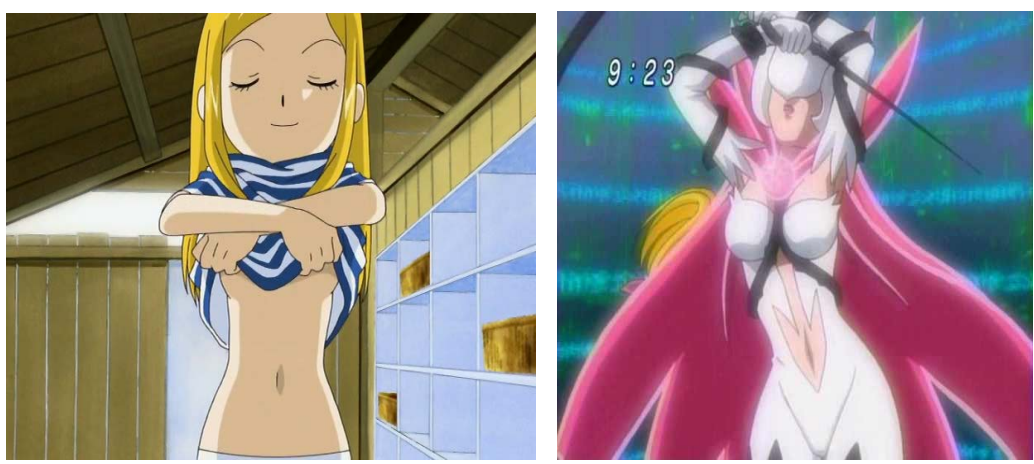

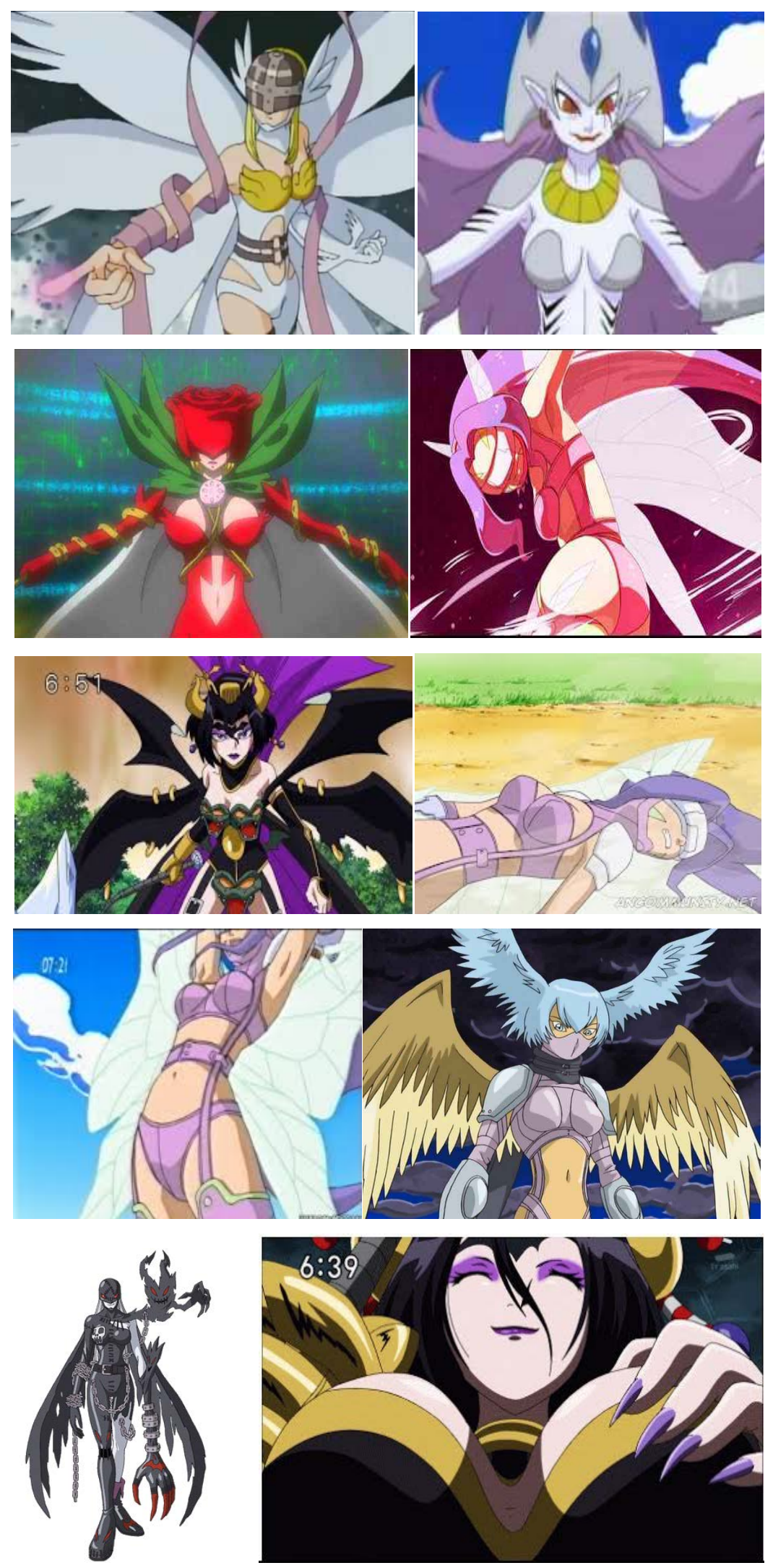

Figure 11. Shots from Digimon TV series. 


\section{Example 4}

Show: Pokemon.

Channel: Cartoon Network \& others.

In the pictures exposed, female characters show the feminine organs all over the seasons in shape for comedy or normal culture (Figure 12).

\section{Example 5}

Above are random scenes from different animes \& cartoons which contain exposure of the female and male body sexual organs (Figure 13).
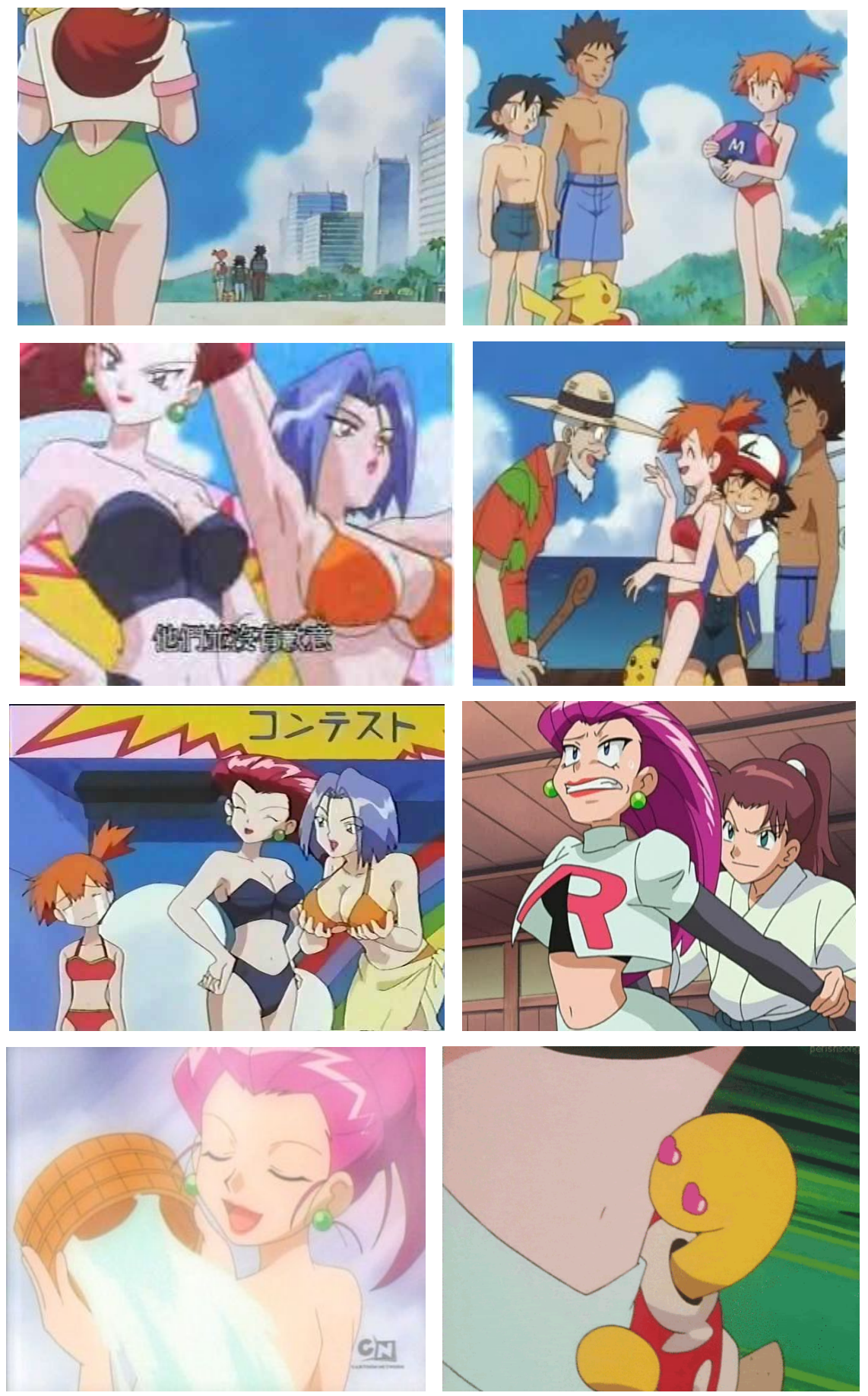


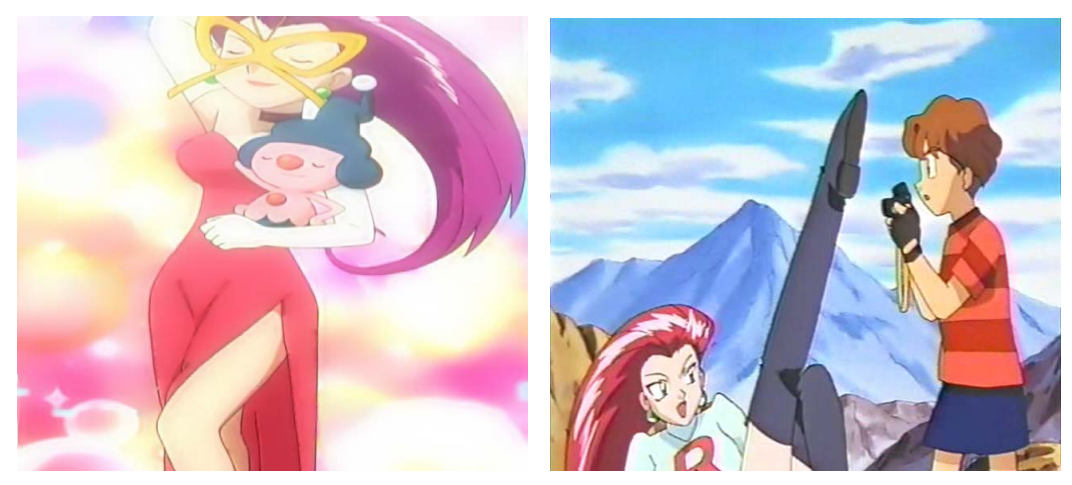

Figure 12. Shots from Pokemon TV series.

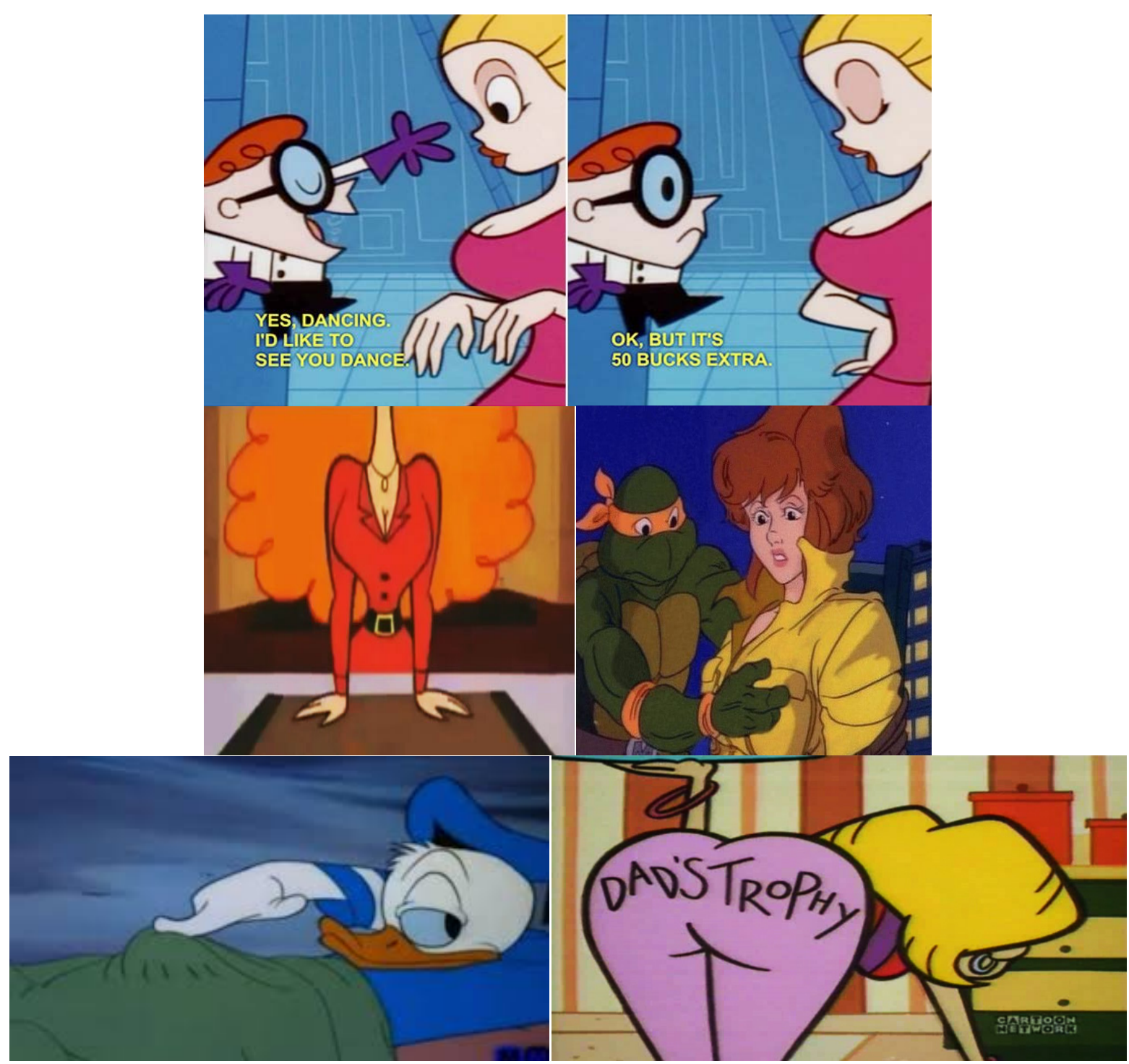

Figure 13. Shots from different TV series.

All this and much more are explicit sexual content that are present in cartoonish content-on purpose or by mistake - but according to above mentioned results, still have their effect on the human brain. 


\subsubsection{Violent Content}

The other drawback of the cartoon which we cover here in the research is the violent content in the cartoon, it is well known in our memories that we do recall a cartoon character that holds on a baseball stick and hits the other character several times on his head, then the offended character begins to feel dizzy in a comedy way and have birds surrounding his head, then become normal seconds later! As a cartoon supposed to be displayed for kids, how would that affect their behaviour, terms and understanding of their surroundings? [9].

In a research performed by Dr. Huisman "Michigan University", it is mentioned that this type of violence delivered for kids, would have one of two possibilities of effects on the child. First, a case called desensitization, which means that the child looses logic thinking of the result of his actions. He becomes unable to predict the correct outcome of his actions, he begins to substitute the cartoon characters with himself and his friends, he then would like to repeat these situations which caused him to laugh-like an adult that would repeat a speech from a movie or a TV Show with a friend to recall laughing - then his mind incorrectly begins to persuade the child that hitting a friend with a hard object is not a matter that would cause harm. Gradually and with excessive violence scenes, the kid's behaviour is programmed to react violently to most of his surroundings actions and situations [9] [10].

The second possibility is fear \& wavering. These actions which a child watches on TV, he feels their outcome defies logic. Hitting a head several times with a hard body should cause serious harm, how does this cause nearly no harm in the show? This causes the child to waver before taking an action in his real life, his brain is no more able to predict the correct outcome of an action, will it be acceptable or would cause serious harm.

Another research performed by Thomas A. Kooijmans "Rochester Institute of technology" concluded that the violence that appears excessively and with no reason in a TV Cartoon Show, cause excessive increase in Adrenaline production which cause instable state of mind. The child then begins to act nervously and aggressively towards normal situations or during his playing time with his mates [11].

Below are some Samples of cartoon violence shot from different world wide known cartoons: (Figure 14).
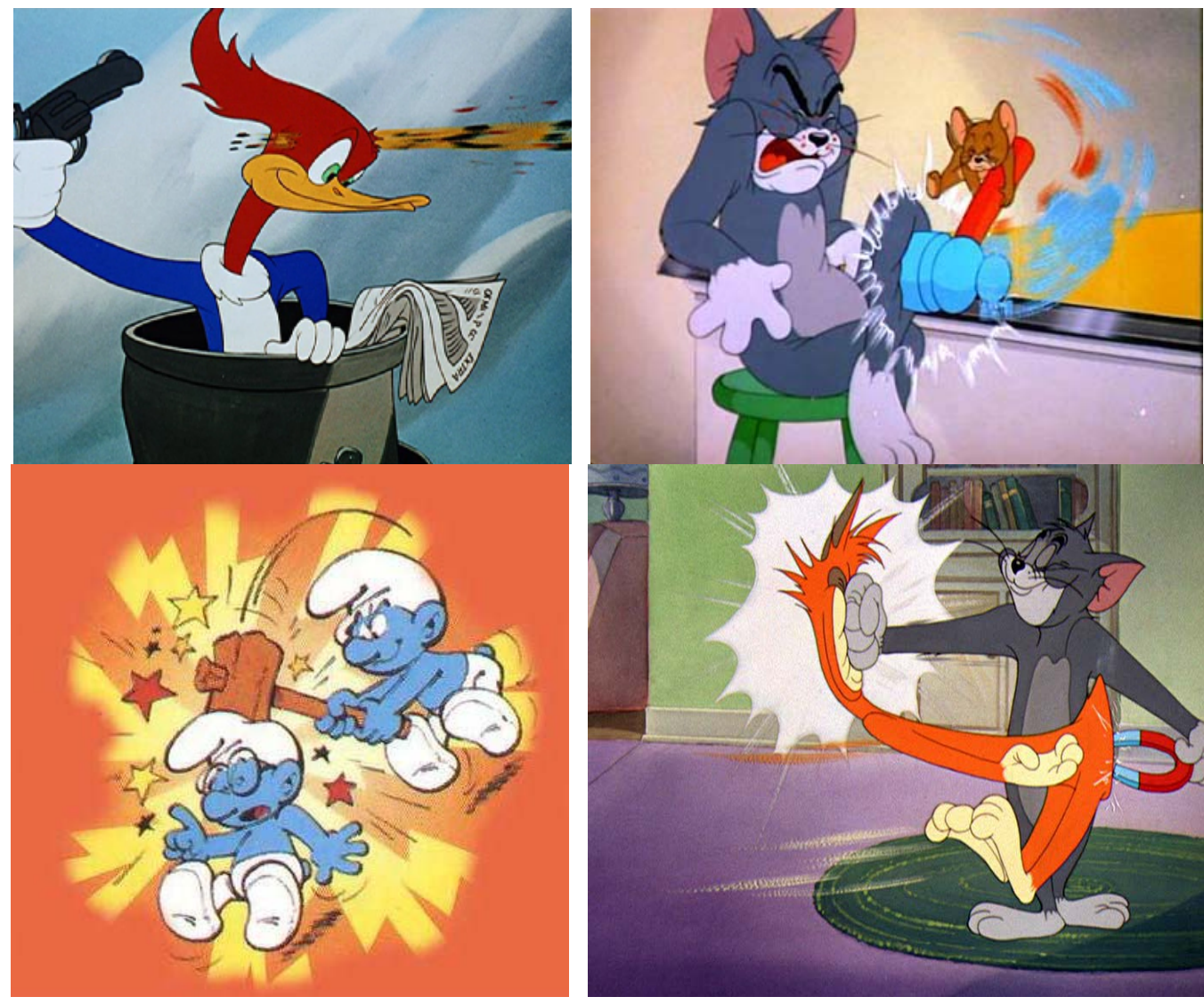

Figure 14. Shots from different TV series exposing violence. 
Steven J. Kirsh Department of Psychology, SUNY-Geneseo, Geneseo, NY 14454, United States. in a paper titled "Cartoon violence and aggression in youth" summed up researches and experiments performed by different psychologists on different ages of childhood subjects.

\section{Laboratory Experiments of Violent Programs Effect on Children Behaviour}

Experiment conducted by Lovass, 1961. Conclude that children viewing animation involving human-like figures that hit and bite one another chose to play with an aggressive toy (i.e., a hitting doll), as opposed to a non aggressive toy (i.e., a ball in a cage), in a greater percentage than children seeing a nonviolent cartoon.

Bandura, Ross, and Ross (1963) conducted an experiment that concluded that children who watched violent cartoon experienced higher aggression in their behaviour noticed in hitting and kicking towards a Bobo doll. On the other hand, toddlers who watched non violent cartoon experienced much less aggression in their behavior.

Although there is concern that when preschoolers watch comedic violence, they will come to learn that violence is funny (Nathanson \& Cantor, 2000), thereby increasing their aggressive tendencies, the research has yet to validate this concern.

\section{Field Experiments of Violent Programs Effect on Children Behaviour}

Field experiment-based research on children in early childhood was not conducted widely. Friedrich and Stein (1973) exposed preschool children to 20 min of Batman and Superman or to a series of neutral live action films. Three times a week, for four weeks.

Then their actions were monitored to assess the effect of the program on the children behaviour. Youth watching the violent cartoons were more disobedient and less tolerant. Also, youth who experienced high levels of aggression prior to the experiment became more aggressive if they watched the violent cartoons than if they watched the nonviolent cartoons [7].

Similarly, Steuer, Applefield, and Smith (1971) in their research concluded that 11 daily 10 min sessions of watching Violent TV programs resulted in greater physical aggression towards peers in comparison to young children watching a series of non-violent cartoons.

Silvern and Williamson (1987) conducted an field experiment to assess the effect of violent comedy cartoon on children behaviour 28 preschool boys and girls were randomly selected.

The experiment took place for three days, involved the assessment of baseline aggression during dyadic play with a classmate, after viewing violent cartoon "Road Runner"; and after the playing of the now classic arcade game Space Invaders, which is considered a violent video game [7] [9].

During the first day of the experiment, baseline aggression during break play was assessed.

During the second day, the children were divided into two groups, the first half of the children played the video game for six min and the other half watched the 6 min long cartoon.

Children were then observed in a free-play session with the toys that were available during the base line condition. During the third day, the two groups exchanged activities, youth who had watched the violent cartoon the day before played the video game and youth.

who had played the video games watched the violent cartoon.

Again, a free-play session with the familiar toys took play. Pro-social behaviour and fantasy play were assessed during each of the three free-play sessions [11].

Results indicated that, relative to baseline levels of responding, after watching the comedy violent cartoon, preschool youth demonstrated higher rates of aggressive behaviour and lower rates of pro-social behaviour.

\section{Conclusions}

As a conclusion of all the research/literature survey:

1) Cartoon is one of the strong factors that does affect an individual's childhood, and takes considerable time from the young toddler schedule.

2) Cartoon is a double edged weapon; it could ruin an individual's childhood through excessive exposing to sexual \& violence content, or could aid in raising a balanced child with a proper mental state.

3) Cartoon could act as a home school, to teach a kid the life experience that is not gained from parents or from school due to facilities that is lacked in the normal academic way or in parents orders. 


\section{References}

[1] Brotherson, S. (2015) Understanding Brain Development in Young Children. Family Science Specialist, NDSU Extension Service.

[2] Ales, D. (1998) Better Brains for Babies. Publication Nos. FACS 01-1, 01-2, 01-4, 01-6 and 01-7. College of Family and Consumer Sciences, University of Georgia.

[3] Jensen, E. (1998) Teaching with the Brain in Mind. Association for Supervision and Curriculum Development, Alexandria.

[4] Bjorkqvist, K. and Lagerspetz, K. (1985) Children Experience of Three Types of Cartoons at Two Age Levels. International Journal of Psychology, 20, 77-93. http://dx.doi.org/10.1002/j.1464-066X.1985.tb00015.x

[5] Bandura, A., Ross, D. and Ross, S.A. (1963) Vicarious Reinforcement and Imitative Learning. Journal of Abnormal and Social Psychology, 67, 601-607. http://dx.doi.org/10.1037/h0045550

[6] Heller, M.S. and Polsky, S. (1976) Studies in Violence and Television. American Broadcasting Company, New York.

[7] Kirsh, S.J. (2006) Cartoon Violence and Aggression in Youth. Aggression and Violent Behavior, 11, 547-557. http://dx.doi.org/10.1016/j.avb.2005.10.002

[8] Aluja-Fabregat, A. and Torrubia-Beltri, R. (1998) Viewing of Mass Media Violence, Perception of Violence, Personality, and Academic Achievement. Personality and Individual Differences, 25, 973-989. http://dx.doi.org/10.1016/S0191-8869(98)00122-6

[9] Gunter, B. (1985) Dimensions of Television Violence. Gower, Aldershot.

[10] Iamurai, S. (2009) Positive Cartoon Animation to Change Children Behaviors in Primary Schools.

[11] Septiadi (2007) Televisi dan Parubahan. Unmuh Press, Surakarta. 